Journal of Language Teaching and Learning, Linguistics and Literature

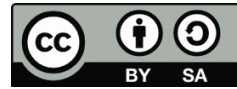

Issued by English study program of IAIN Palopo

ISSN 2338-4778 (Print)

ISSN 2548-4192 (Online)

Volume 7, Number 2, December 2019

pp. $21-31$

\title{
Intrinsic and Extrinsic Motivation of English Education \\ Graduation Students Batch 2018 in Accomplishing Academic \\ Performance
}

\author{
Elizabeth $^{1} \&$ Ouda Teda Ena ${ }^{2}$ \\ @Lizzie.lizaa@gmail.com \\ University of Sanata Dharma, Indonesia
}

Received : 12 Agustus 2019; Accepted : 20 November 2019

\begin{abstract}
This research is aimed to identify intrinsic and extrinsic motivation of graduate students in English Education Master Program batch 2018. However, motivation became the most dominant factor to build in relation to the academic performance. The research is limited to one research question "what are the factors of graduate students' intrinsic and extrinsic motivation to build in relation to their academic performance?". To answer the research question, the researcher employed descriptive qualitative research. The researcher conducted semi-structure interview with nine English Education graduate students. The participants are purposively selected. The result showed that intrinsic motivation is more dominant than extrinsic motivation to build in relation to the academic performance of English education graduate students batch 2018. In intrinsic motivation, the initial purpose or goal-oriented of English education graduated students batch 2018 for entering the college is the most dominant factor in order to build in relation to the academic performance. In extrinsic motivation, the role of supportive peers is higher than other characteristics of extrinsic motivation.
\end{abstract}

Keywords: intrinsic motivation; extrinsic motivation; academic performance 


\section{Introduction}

Motivation in general can be defined as a motive or reason which stimulate people to do action as their willingness, desire, or passion as targeted goals. Dornyei (2005) argued that motivation is human navigation. It can either give direction or energize human behaviour. Therefore, motivation is one of the important element in higher education. it can be function as navigation in the learning process. It will also increase students' interest to learn. Further, motivation energize the students to learn. It can lead students' attitude toward the learning process itself. In this research, the researcher will be focused on the students' motivation in the academic performance. According to Deci and Ryan (1985), motivation can predict students' academic performance. Therefore, motivation is one of the important things for educators. Motivation can predict learning outcome and learning achievement.

Students' motivation is one of the variable that has been significantly affect learning success. According to Reiss (2012), students' motivation or human motive can be divided into two types which are intrinsic motivation and extrinsic motivation. Intrinsic motivation is the reason for people to do something due to his or her need and desire. There is no specific reason for the person in doing something since s/he love to do it for his or her own sake and pleasure. Deci and Ryan (1985) argued that intrinsic motivation is derived from personal need of competence and self determination. Thus, students with intrinsic motivation try to develop themselves in order to achieve their learning goal. On the other hand, extrinsic motivation is a motive stimulated by some external factors like environment, reward,and punishment. Deci and Ryan (1985) stated that extrinsic motivation is "a means to an end". However, intrinsic and extrinsic motivation are interrelated to each other. Some research have shown that extrinsic rewards can lead to intrinsic motivation. For example, students who always submitted the assignments on time (external factor) will foster a sense of responsibility within his or herself.

Considering the importance of motivation in accomplishing academic performance. Then, the researcher is aimed to find out some factors of motivation (either intrinsic or extrinsic) to build in relation to the academic performance of English Education Graduate students batch 2018 in one of private university in Yogyakarta.

\section{The conceptualisations of motivation}

In understanding the conceptual of intrinsic and extrinsic motivation, the researcher used self determination theory from Dornyei. Self Determination 
Theory (SDT) is a framework theory of motivation that explain the various intrinsic and extrinsic proponents of motivation. According to Dornyei (1998), self determination theory is one of the features in motivation theories. There are some previous studies related to self determination theory focused on intrinsic and extrinsic motivation. Douglas Brown $(1990,1994)$ as cited in Dornyei $(2005)$ claimed that the importance of intrinsic motivation is influenced by extrinsic motivation such as the traditional school settings. Other experts of self determination theory, Luc and Robert in Dornyei (1998) describe that the components of intrinsic and extrinsic motivation are interrelated to each other. In addition, they emphasized that the classroom practices can affect the learners' level of self determination. Dornyei (1998) added that learners' motivation can be increased by fostering learner autonomy in classroom. However, Dornyei (1998) underlined that motivation is depend on learners' responsibility to take efforts and strategies in learning rather than the factors outside. it means how the learner recognize their own Learning successes and failures depends on conditional of the learner in taking their responsibility in the learning process. However, the proponent of intrinsic motivation can turn an individual's behaviour to be more positive.

According to Dornyei (1998), there are three types of intrinsic motivation. They are:

“(a) to learn (engaging in an activity for the pleasure and satisfaction of understanding something new, satisfying one's curiosity and exploring the world); (b)towards achievement (engaging in an activity for the satisfaction of surpassing oneself, coping with challenges and accomplishing or creating something); and (c) to experience stimulation (engaging in an activity to experience pleasant sensations)" (p.121)

However, there are three types of extrinsic motivation according to Dornyei (1998):

“(a) Introjected regulation involves externally imposed rules that the student accepts as norms he/she should follow in order not to feel guilty. (b) Identified regulation occurs when the person engages in an activity because he/she highly values and identifies with the behaviour, and sees its usefulness. The most developmentally advanced form of extrinsic motivation is (c) integrated regulation, which involves choiceful behaviour that is fully assimilated with the individual's other values, needs and identity (e.g. people deciding to learn a language which is necessary for them to be able to pursue their hobbies or interests)." (p.121)

\section{Method}

In analyzing the factors of intrinsic and extrinsic motivation of English 
Education graduate students, the researcher applied descriptive qualitative method. According to Ary, Jacobs, and Razavieh (2002), "qualitative research focuses on understanding social phenomena from the perspective of human participants in the study" (p.22). Even, Bodgan and Biklen (2003) added that "one of features of qualitative research is that it is descriptive and it concerns in providing description of a phenomenon that occurs naturally without any intervention of an experiment or an artificially contrived treatment" (p.28). This research was intended to dig deeper on the factors of intrinsic and extrinsic motivation graduate students to build in relation to their academic performance. The researcher described naturally a phenomenon of graduate students' motivation without any treatment or experiment. A qualitative research method is the most appropriate method here because it gives depth understanding the phenomenon of intrinsic and extrinsic motivation. Therefore, it is the best method to analyze the factors of intrinsic and extrinsic motivation graduate students in accomplishing academic performance.

The research was conducted in one of private university in Yogyakarta. The researcher conducted the data through semi-structured interview with nine selected participants. The interview was being recorded. The data were collected in November. The date, time, and place for the interview was negotiated with each participant. Then, the researcher identified the data from the interview section. Coding was used by the researcher in order to analyze the data. However, the data analysis was in the form of descriptive qualitative by researcher's interpretation.

The Participants of this study were the students of English Education Master Program (EEMP) batch 2018 in one of private university in Yogyakarta. However, there are twenty two graduate students learning in English Education Master Program batch 2018. Yet, the researcher selected only nine graduate students out of twenty two graduate students to be interviewed through purposive sampling. Barreiro \& Albandoz (2001) stated that "purposive sampling is the one in which the person who is selecting the sample is who tries to make the sample representative, depending on his opinion or purpose, thus being the representation subjective" (p.4). The reason of choosing purposive sampling was the researcher want to choose the participants who meet the categories of passionate in education and non-passionate in education. The categories are crucial to establish personal motivation in accomplishing academic performance. Then, purposive sampling was used to seek for detail and depth understanding in a small number of participants.

There were two research instruments used in this research. They were human Instrument and interview guideline. According to Donald Ary, Sorensen, \& Razavieh (2010), human instrument is the primary instrument in qualitative 
research. Hence, the researcher plays a role as a human instrument in this research for collecting and analyzing the data. According to Lincoln and Guba (1988), the concept of human instrument is an instrument to emphasize the role of researcher to play in the inquiry since qualitative research studied about human experiences and situations, then the researcher is flexible enough to capture the complexity of the human experience and capable of adapting and responding to the environment. Thus, the researcher acted as the human instrument in order to collect the data from participants' life story. The researcher talked to the participants in setting, observed the activities, and recorded the information in interview.

The second instrument employed in this research is interview guideline. In order to gather the information, the researcher utilized interview guideline for capturing the thoughts, feelings, and opinions about the situations (Donald Ary, Sorensen, \& Razavieh, 2010). The researcher as the human instrument interviewed the research participant in personally and recorded the answers. Personal interview will provide the desired information from the participants (Donald Ary, Sorensen, \& Razavieh, 2010). However, the interview guideline employed in this research consisted of ten questions regarding to intrinsic and extrinsic factors of motivation. Those questions helped the researcher to find out the factors of intrinsic and extrinsic motivation in English Education graduate students batch 2018 . The researcher analyzed the data by using the conceptual of motivation theory to investigate the deeper personal motivation of each participant.

In this research, the researcher utilized Creswell's (2009) to analyze the gathered data. There were six steps employed. They were organizing and preparing the data for analysis, reading all the data, coding, representing the data in qualitative narrations, using the coding to generate categories or themes for analysis and interpreting the data. First, the researcher organized and prepared the data for analysis by transcribing the data and typing notes from the interviews. Second, the researcher read and re-read notes and transcripts. Third, the researcher analyzed the data by coding the data. Fourth, the researcher utilized the coding process to generate categories or themes for analysis. The themes and categories were analysed by drawing on the concept of motivation. Fifth, the researcher represented the themes into a qualitative narration. Sixth, the researcher interpreted the data through personal interpretation and compared with the theories.

\section{Results \& Discussion}

This part would answer one research question "what are the factors of graduate students' intrinsic and extrinsic motivation to build in relation to their academic performance?". The researcher analyzed the factors of intrinsic and 
extrinsic motivation through semi-structured interview to the nine selected participants in english education batch 2018 based on Dornyei (1998) theory and Pintrich (2003) Theory developped by Shia (1998) theory. In addition, the researcher made the blueprint interview and analyzed the data based on Dornyei (1998) theory and Pintrich (2003) which is developped by Shia (1998). They illustrated eight criterion of the factors in intrinsic and extrinsic motivation. The factors included in intrinsic motivation are learners' personal value, learners' personal needs for achievement and learners' personal mastery goals. extrinsic motivation involves peer acceptance, fear of failure, learning environment, the broader context, the nature of interaction with significant others. However, the factors of intrinsic and extrinsic motivation build graduate students' academic performance. In addition, all of the factors are interrelated to build in relation their academic performance. Here, the researcher chose the top factors of intrinsic motivation factors and extrinsic motivation in order to discuss further.

The first indicator of intrinsic motivation appeared in the the result of data coding is learners' personal goal oriented.

\section{1. purpose/goal-oriented}

The most dominant factor in English Education graduate students batch 2018 is their own purpose and their personal goal-oriented to learn in English Education Master Program. This factor is always be the basic motive of the graduate students to have motivation in taking master's education program. When they feel demotivated then the students remind themselves to their purpose and their learning goal at the first time for studying at master program.

\section{Participant 1 :}

"the things that always motivate me is my own purpose and my goal-targeted at the first time to learn here in English Education Master Program. I've ever failed for taking master program in the past. I kick myself out from my job so I can be more focused on my own study. I have no job right now. Thus, I expect that there is no more failure. I have to finish what I have started. I want to graduate soon with master degree"

\section{Participant 2 :}

"I am a student mother here. I will do my best since I pay the college tuition by myself, so I don't want to waste it. it's my responsibility to finish what l've started."

\section{Participant 3:}

"I always encourage myself by asking to myself 'why do you here?'it can remind me to my initial purpose and goal-targeted before entering this college." 
All of the participants above have shown that learners' personal goal and purpose to study in master program have motivated them. Dornyei (1998) said that "human action is caused by purpose, and for action to take place, goals have to be set and pursude by choice" (p.120). However, It can be seen from their attendance list that those students never missed the class. From the results of interview showed that students' self-awareness is high enough to pursue their master degree. In addition, some of the participants have higher self-encouragement to take new responsibility as a graduate students. In addition, they have self-encouragement to finish what they have started before.

\section{Passionate VS non-passionate in education}

\section{Non-Passionate students}

Seven participants out of nine said that they have no passion in teaching and education area. They said that the decision to take master program in education area is their parents. Family authorithy become the main motive to learn in english education master program.

Participant 4 told that her parents illustrate that being a mom is being a teacher:

"to be honest, actually being a teacher is not my passion. my father is a teacher. He give me a description to be a teacher. I ever said to my parents that I think I can not be a teacher. Then, my parents said it's oke, you can learn it. Then, I think that becoming a teacher is useful for our daily life, for instance being a mom needs skill of teacher to educate kids. Thus, I take English Education Master program now since my background of the study before is English department."

Participant 5 told that his parents encourage :

"my parents asked me to continue my education at master degree especially in education area.."

Participant 6 hesitate her skill to teach and to speak in front of people:

"being a teacher is hard for me....I still need to improve myself especially for public speaking. I'm too shy to speak in front of the people."

The interview results show that the majority of graduate students batch 2018 in english education study at master program because their parents asked them to continue their study in education area. Even, it is not their passion itself to work in education area. Here, the non-passionate students are categorized as the factor of extrinsic motivation since the authority of the family is more dominant than the needs or desire itself to study at English Education master program. As Dornyei said that "when the person engages in an activity because he/she highly values and identifies with the behaviour, and sees its usefulness" 
(p.121). Here, the graduate students get the illustrate and the insight for being a teacher from their parents expectation/authorithy. Then, it will be categorized to the extrinsic motivation.

\section{Passionate students}

there are three participants out of nine answered that they have very passionate on teaching.

\section{Participant 7 :}

"I want to be a lecturer so I decide to continue my study at master program in education"

\section{Participant 8 :}

"I am very passionate on teaching since the demand of my profession is to develop myself as a teacher."

\section{Participant 9 :}

"I want to upgrade degree as an educator since I have to deal with teacher training."

this passionate students can be categorized to the factor of intrinsic motivation. Dornyei (1998) added that:

"three subtypes of intrinsic motivation are

(a) to learn (engaging in an activity for the pleasure

and satisfaction of understanding something new, satisfying

one's curiosity and exploring the world);

(b) towards achievement (engaging in an activity for the satisfaction of surpassing oneself, coping with challenges and accomplishing or creating something);and

(c) to experience stimulation (engaging in an activity to experience pleasant sensations)." (p.121)

\section{Learners' personal needs}

participant 8 needs to develop skill :

"my goal-targeted is being a lecturer in the future, so I need to learn a lot of new things"

participant 9 needs to develop skill: 
"I need to upgrade my skill and my knowledge to reach my goal engaged in education"

participant 2 needs for achievement :

"I want to make all lecturers believe in my capabilities. I can do it"

participant 5 needs for achievement :

"I love to learn... I need to learn"

in extrinsic motivation, peer acceptance posit the higher factors than other extrinsic factors in order to build in relation to their academic performance.

\section{Peer acceptance}

\section{Participant 1:}

"my classmates are very supportive. If I don't understand in a certain part, then I asked to them, they always be very welcome to explain and to share their knowledge to me."

\section{Participant 2 :}

"my classmates are easygoing. They are so helpful and informative. I feel so comfortable to interact with them all"

\section{Participant 3:}

"my friends are great people but they still accept me and support me like a family. Although my capabilities feels so far away than my friends, they still support and give me motivation as well. They do really understand our character. I feel so comfortable and safe learning in the classroom."

All of the participants said that their peer or friends in the classroom are so supportive, helpful, easygoing, and informative. However, graduate students feel that their friends in the classroom are the most dominant factor of extrinsic motivation for them. They feel like they do not fight alone, but they have family here. As Dornyei (1998) described that behavior becomes valued and judged important for the individual.

However, other factors of extrinsic motivation like the way lecturers teach, deliver material, interact with students in the learning process, and the clarity of the materials, are the second top of extrinsic motivation affected graduate students' learning motivation.

\section{Lecturers, Learning Materials,and lecturing method}

\section{Participant 4:}

"the way lecturer teach and deliver materials in class is really good. They open our 
Elizabeth \& Ouda Teda Ena

Intrinsic and Extrinsic Motivation of English Education Graduation Students

Batch 2018 in Accomplishing Academic Performance

insight and perception, they try to dig our point of view in different side and angle."

\section{Participant 5:}

"our lecturers are capable in teaching and delivering the materials. They have good knowledge to teach, and interact with their students.

\section{Participant 6:}

"our lecturers are very concerned to their students, not just the materials, but from the students' side either their psychology or their comfortable in the classroom. The quality of their teaching are very good since they really encourage the students to improve themselves."

Lecturers who have performance, ability the material and the way to teach both will make students more motivated to attend lectures, and learn the materials. In other words, the role of lecturers is very important to increase students'motivation Dornyei (1998) argued that "the form of extrinsic motivation, coming entirely from external sources such as rewards or threats (e.g.teacher's praise or parental confrontation)" (p.121)

However, interview result have shown that all students are satisfied and motivated enough to join the lecturer. Besides, the interview result showed that the good interactions between the lecturers and students through learning process in the classroom helps a lot in improving student confidence (McGlynn, 2008).

\section{Conclusion}

Based on the finding and discussion above, it can be concluded that learning motivation of english education graduate students batch 2018 is dominated by intrinsic motivation than extrinsic motivation. Yet,there are two factors that make a person be motivated in learning, namely:

1. intrinsic motivation : a motive formed by internal factor, like: students' goaloriented/purpose, students' personal needs for achievement, students' personal value.

2. extrinsic motivation: a motive formed by external factor, such as : peer acceptance, lecturer, lecturing method/activity, learning materials, learning environment.

However, this research is expected to be used as an input and important information to be more concerned to students' motivation.

\section{References}


Ary, D., Jacobs, L.C., Sorensen, C., \& Razavieh, A. (2002). Introduction to Research in Education (6 ${ }^{\text {nd }}$ ed.).Foth Worth: Wadsworth Thomson Learning.

Ary, D., Jacobs, L.C., Sorensen, C., \& Razavieh, A. (2010). An Introduction to research in education. Belmonth: Wadsworth.

Barreiro, P.L., \& Albandoz, J.P. (2001). Population and Sample. Sampling Techniques, Management Mathematics for European Schools.

Bodgan, R.C., \& Biklen, S.K. (2003). Qualitative Research for Education: An Introduction to Theories and Methods. New York: Pearson Education Group.

Creswell, J. (2009). Research design: Qualitative, quantitative and mixed methods approaches. Los Angeles: SAGE Publications Inc.

Deci, E. L., \& Ryan, R. M. (1985). Intrinsic motivation and self-determination in human behavior. New York, NY: Plenum.

Deci, E. L., Koestner, R., \& Ryan, R. M. (2001). Extrinsic Rewards and Intrinsic Motivation in Education: Reconsidered Once Again. Review of Educational Research, 71(1), 1-27. doi:10.3102/00346543071001001.

Dörnyei, Z. (1998). Motivation in second and foreign language learning. Language Teaching, 31(3), 117-135. doi:10.1017/S026144480001315X.

Dornyei, Z. (2005). The psychology of the language learner individual differences in second language acquisition. London: Lawerence Erlbaum Associates.

Guba, E.G., \& Lincoln, Y.S. (1988). Do inquiry paradigms imply inquiry methodologies? In D. M. Fetterman. (ed.) Qualitative approaches to evaluation in education: the silent scientific revolution. (pp. 89-115.) London: Praeger.

McGlynn, A. P. (2008). Beyond behaviour management: Manage or motivate? Education Digest, 73(6), 19-22.

Pintrich, P. R. (2003). A motivational science perspective on the role of student motivation in learning and teaching contexts. Journal of Educational Psychology, 95(4), 667-686. doi:10.1037/0022- 0663.95.4.667.

Reiss, S. (2012). Intrinsic and Extrinsic Motivation. Teaching of Psychology, 39(2), 152-156. doi:10.1177/0098628312437704.

Shia, R.M. (1998). Academics intrinsic and extrinsic motivation and metacognition: Assessing academic intrinsic motivation: A look at student goals and personal strategy (Thesis)/ Wheeling Jesuit University, West Virginia. 